\title{
Development of Population Tariffs for the CarerQol Instrument for Hungary, Poland and Slovenia: A Discrete Choice Experiment Study to Measure the Burden of Informal Caregiving
}

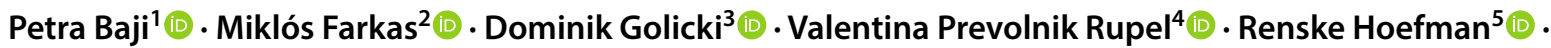

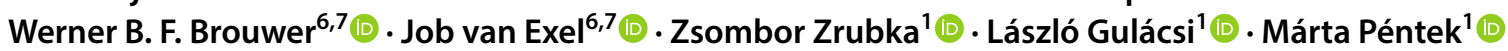

Published online: 23 March 2020

(c) The Author(s) 2020

\begin{abstract}
Background The CarerQol instrument can be used in economic evaluations to measure the care-related quality of life of informal caregivers. Tariff sets are available for Australia, Germany, Sweden, the Netherlands, the UK, and the USA.

Objective Our objective was to develop tariff sets for the CarerQol instrument for Hungary, Poland and Slovenia and to compare these with the existing value sets.

Methods Discrete-choice experiments were carried out in Hungary, Poland and Slovenia. Data were collected through an online survey between November 2018 and January 2019, using representative samples of 1000 respondents per country. Tariffs were calculated from coefficient estimates from panel mixed multinomial logit models with random parameters.

Results All seven CarerQol domains contributed significantly to the utility associated with different caregiving situations. Attributes valued highest were 'physical health' (tariffs for no problems were 15.6-21.8), 'mental health' (18.1-18.9) and 'fulfilment' (16.3-22.9). Value sets were comparable across the countries, although in Poland 'a lot of fulfilment' was valued higher (22.9) than in Hungary (16.3) and Slovenia (17.1). Compared with existing value sets, in the three Central European countries, 'fulfilment' was more important, whereas 'financial problems' were less important.

Conclusion For the first time in the Central and Eastern European region, country-specific tariffs are now available for the Hungarian, Polish and Slovenian versions of the CarerQol instrument. This facilitates inclusion of the impact of informal care in economic evaluations. Our results can be used to develop and evaluate country-specific health policy strategies to support informal caregivers. The differences found in informal care preferences highlight the limited transferability of CarerQol tariffs across European regions.
\end{abstract}

Electronic supplementary material The online version of this article (https://doi.org/10.1007/s40273-020-00899-2) contains supplementary material, which is available to authorized users.

\section{Introduction}

Informal care is a common phenomenon and, in most countries, constitutes an important part of the total care received by people who need support as a result of disease or ageing. In Organisation for Economic Cooperation and Development (OECD) countries, $8-22 \%$ of the population aged $>50$ years

Petra Baji

petra.baji@uni-corvinus.hu

1 Department of Health Economics,

Corvinus University of Budapest, Fővám tér 8 , Budapest 1093, Hungary

2 Department of Accounting and Finance, University of Bristol, Priory Road Complex, Bristol BS8 1TU, UK

3 Department of Experimental and Clinical Pharmacology, Medical University of Warsaw, ul. Banacha 1b, 02-097 Warsaw, Poland

4 Institute for Economic Research, Kardeljeva ploščad 17, 1000 Ljubljana, Slovenia

5 The Netherlands Institute for Social Research, Den Haag, The Netherlands

6 Erasmus School of Health Policy \& Management (ESHPM), Erasmus University Rotterdam, PO Box 1738, 3000 DR Rotterdam, The Netherlands

7 Erasmus School of Economics (ESE), Erasmus University Rotterdam, PO Box 1738, 3000 DR Rotterdam, The Netherlands 


\section{Key Points}

We have developed the first tariff sets for the CarerQol instrument in the Central and Eastern European (CEE) region by establishing country-specific tariffs for Hungary, Poland and Slovenia.

In the three CEE countries, 'fulfilment' was more important than in existing value sets from Australia, Germany, Sweden, the Netherlands, the UK, and the USA, whereas 'financial problems' were less important.

Differences in informal care preferences indicate that CarerQol utility scores are not transferable without adjustment across European regions, which needs to be considered in economic evaluations.

provides weekly or daily informal care to a family member or friend $[1,2]$. Providing informal care can be fulfilling $[3,4]$, but it may also be burdensome and time consuming, making it difficult for caregivers to combine caregiving tasks with usual activities [5]. Caregiving thus can affect the time use of caregivers, their relationship with the care recipient and their mental or physical health [5]. Given their relationship with the care recipient, caregivers are likely to be affected by both the fact that a loved one is ill (the "family effect') and the impact of caregiving (the 'caregiving effect') [6]. The family effect can also occur in a broader group than just caregivers. Thus, interventions improving the health status of patients affect not only their quality of life but also that of their caregivers and family members. Depending on the perspective taken, these costs and (health or wellbeing) effects should be included in economic evaluations of health interventions [7-10].

The CarerQol instrument was introduced in 2006 to quantify the impact of providing informal care on the quality of life of caregivers and has since been validated in different populations and caregiving contexts $[8,11,12]$. The CarerQol can be used to describe a caregiving situation using seven questions on care-related experiences (i.e. the CarerQol-7D descriptive system) and a visual analogue scale (i.e. the CarerQol-VAS), which measures the happiness of caregivers.

Similarly to common preference-based health status measures such as the EuroQoL 5-Dimensions (EQ-5D) instrument, CarerQol utility scores ('tariffs') are available that reflect societal preferences for the care states that can be distinguished using the CarerQol-7D descriptive system and value them in terms of care-related quality of life on a scale from 0 (worst caregiving situation) to 100 (best caregiving situation). Tariff sets for the CarerQol-7D have been developed using representative samples of the population in six countries, namely, Australia, Germany, Sweden, the Netherlands, the UK, and the USA [13, 14]. While it is not straightforward to add care-related quality-of-life scores to patient health-related quality of life, used in common cost-utility analyses, they can be used as a primary outcome measure in economic evaluations of interventions directly targeted at improving caregivers' quality of life. Moreover, they can be presented next to patient outcomes as one element in a multi-criteria decision analysis to explicitly inform policy makers about all effects of a certain intervention on patients and caregivers [13].

To date, no tariff sets for the CarerQol-7D exist for Central and Eastern European (CEE) countries. However, it is plausible that societal preferences for caregiving situations in these countries would differ from those in the six countries for which tariffs are currently available. Differences in preferences for caregiving states could be related to differences in economic development, social and cultural backgrounds, values and attitudes towards informal care, the role of families in providing long-term care, and the infrastructure of and access to long-term care services [13, 15].

Thus, the primary objective of this study was to develop country-specific tariff sets for the CarerQol-7D instrument for three Central European countries: Hungary, Poland and Slovenia. In addition, we aimed to compare the results of the three countries with each other and with the existing value sets to assess the differences within the region and with other European countries (Germany, Sweden, the Netherlands, the UK), as well as with Australia and the USA.

To ensure comparability of findings, we used the same discrete-choice experiment (DCE) design and analytical techniques that were successfully applied previously to develop value sets for the aforementioned six countries [13, 14].

\section{Methods}

\subsection{The CarerQol Instrument}

As briefly mentioned, the CarerQol instrument consists of two parts: the descriptive system (CarerQol-7D) and a measure of happiness (CarerQol-VAS). The CarerQol-7D can be used to describe the caregiving experience on seven distinct domains, including two positive domains (fulfilment and support) and five negative domains (relational problems, mental health problems, physical health problems, financial problems and problems with daily activities). Respondents can respond on a three-level answering scale per domain, reflecting no, some, or a lot of problems. Different combinations of levels in the seven domains captured in the descriptive system of the CarerQol-7D allow $2187\left(3^{7}\right)$ 'caregiving states' to be distinguished. The tariff set can be used to 
compute a care-related quality-of-life score for each state, reflecting the relative societal preference for the given state. Typically, these preferences are derived from a representative sample of the general population.

\subsection{Data}

This study was part of a larger cross-sectional survey on informal care; details of the research have been described elsewhere [16]. In brief, data were collected between November 2018 and January 2019 in Hungary, Poland and Slovenia using a web-based questionnaire. Recruitment was carried out and data collected via commercial online panels in each country by a market research and public opinion polling company (Big Data Scientist Ltd.) via their partnership with these panels. Quotas were applied to ensure the representativeness of the sample by age (up to age 65 years and a sizeable sample above), sex, educational level, and residency. The target sample size was 1000 respondents per country to ensure representativeness of the sample and to involve a reasonable number of participants with some experience with informal care, either as a recipient or a provider.

\subsection{The Questionnaire}

For reasons of comparability, we adapted the same study design and the original questionnaire used to obtain value sets in the Netherlands and later in Australia, Germany, Sweden, the UK, and the USA $[13,14]$. We refer to these as 'reference countries' in the remainder of the paper.

The translations of the CarerQol attributes and their levels into Hungarian, Polish and Slovenian were based on independent forward-backward translations involving native in-country investigators and a professional translating agency. Back translations were reviewed by the investigators. The developers of the original questionnaire were involved in the process of setting up the study. The questionnaire was identical in all three countries, except for the language used.

The main part of the questionnaire used in this study was the DCE task. The final version was tested in a small pilot study ( $N=5$ per country) to assess the feasibility of the different language versions, as the DCE itself had already been conducted successfully in previous multi-country research [13]. As in the original surveys, after completing the DCE task, respondents were asked how difficult it was for them to complete the DCE task and also about some details of the care recipient and caregiving situation they had in mind when filling in the DCE task (i.e. who the care recipient was, how long and intense caregiving would be, and which problems they had). Further questions related to sociodemographic characteristics and the caregiving experiences of respondents. At the end of the survey, those who selfreported as informal caregivers completed the normal CarerQol questionnaire.

\subsection{The Discrete-Choice Experiment Task}

In the DCE task, respondents were asked to imagine that they provided care or support to a loved one because of an illness, disability or infirmity of old age. They were also asked to keep the same care recipient in mind during the whole experiment. Then, we described a number of caregiving situations using the seven domains of the CarerQol-7D. We presented the respondent with ten choices between two caregiving situations described with the CarerQol domains and levels (see an example in Online Resource 1). In each choice scenario, respondents were asked to indicate which option they preferred. Like in the original survey carried out in the Netherlands, we used colour coding for the visual representation of the information: positive attribute levels were displayed in green text, negative levels in red text and intermediate levels in orange.

The DCE design applied the priors from the original survey in the Netherlands [13, 14]. This provided an efficient experimental design, constructed in Ngene software (ChoiceMetrics, Australia), optimized for D-efficiency. The underlying utility function consisted of two dummy variables per CarerQol-7D domains, interaction terms for all combinations and a constant term for the first alternative in the choice set. The design contained 40 choice sets, which were blocked into four groups (i.e. each respondent was presented with ten choice sets in the survey). See more about the creation of the design in Hoefman et al. [13, 14].

\subsection{Ethics}

Ethical approval was obtained from the Hungarian Medical Research Council (Nr. 35286-2/2018/EKU), the Bioethical Committee of the Medical University of Warsaw in Poland (AKBE/204/2018) and the National Medical Ethics Committee (Nr. 0120-458/2018/4) in Slovenia. Respondents were informed that participation in the survey was completely voluntary and that their data would remain anonymous and would not be linked to personal information, such as their name or address, and would be used solely for scientific purposes. Respondents needed to provide their informed consent at the start of the survey and were required to confirm their consent at the end of the survey.

\subsection{Analysis}

The DCE was analysed using a panel mixed multinomial logit (MMNL) model, as was used in the previous studies aiming to derive population tariffs. Using this model would 
increase the comparability of results with those of the previous studies. The MMNL method also allows for the presence of unobservable preference heterogeneity in the population and the correlation of responses across observations (panel structure) [17]. Regression analyses were carried out separately for the three countries. In the regression models, we included random parameters allowing them to be correlated across individuals. An alternative specific constant was only included for Slovenia as it was insignificant for Hungary and Poland. We did not include interactions among attributes for any of the countries as they did not significantly improve model fit. Coefficients of 'some support' and 'a lot of support' for Poland did not show the expected order. Since they were insignificantly different from each other $(p=0.23)$, we collapsed these attribute levels.

To estimate tariffs, individual-specific (conditional) parameters were estimated based on the MMNL estimates [18]. Although the state of 'death' is often applied as an anchor in health state valuations [19], it would not have been appropriate to use 'death' as the opposite of an ideal caregiving situation. Therefore, the worst informal care situation defined by the CarerQol-7D was applied and the means of the individual-specific parameters were rescaled to represent CarerQol-7D utility scores ranging from 0 (worst informal care situation) to 100 (best informal care situation). The standard errors of the tariffs were calculated by rescaling the standard errors of the MMNL population parameters. Analyses were performed in Stata 15.1 (StataCorp, Texas, USA).
To illustrate the differences and similarities between domain importance in the different countries, the relative weights of the domains in the total score were plotted (Fig. 1) for each country involved in our study and for the reference countries. Moreover, CarerQol-7D utility scores were calculated for six selected caregiving situations and were presented in a radar plot (Fig. 2), created in Microsoft Excel. These six caregiving situations were selected to (1) be easy to explain and imagine, (2) cover states from the entire scale from the worst to the best situation, and (3) include some of the most frequent caregiving situations observed in real life (as observed in the caregivers in our dataset). Additionally, CarerQol-7D scores were calculated for current informal caregivers in our samples using Hungarian, Polish, Slovenian and the original Dutch tariffs.

\section{Results}

Characteristics of respondents in the samples are summarized in Table 1. The average age of the respondents was $53.2 \pm$ standard deviation 15.1 in Hungary, $45.1 \pm 15.7$ in Poland and $46.4 \pm 16.0$ in Slovenia, respectively. The share of women was between 51 and $53 \%$. The majority of respondents had some experience with informal care, either as a care recipient, as a caregiver, or by knowing someone who provided or received such care. Characteristics of current informal caregivers have been analysed and presented elsewhere [16].

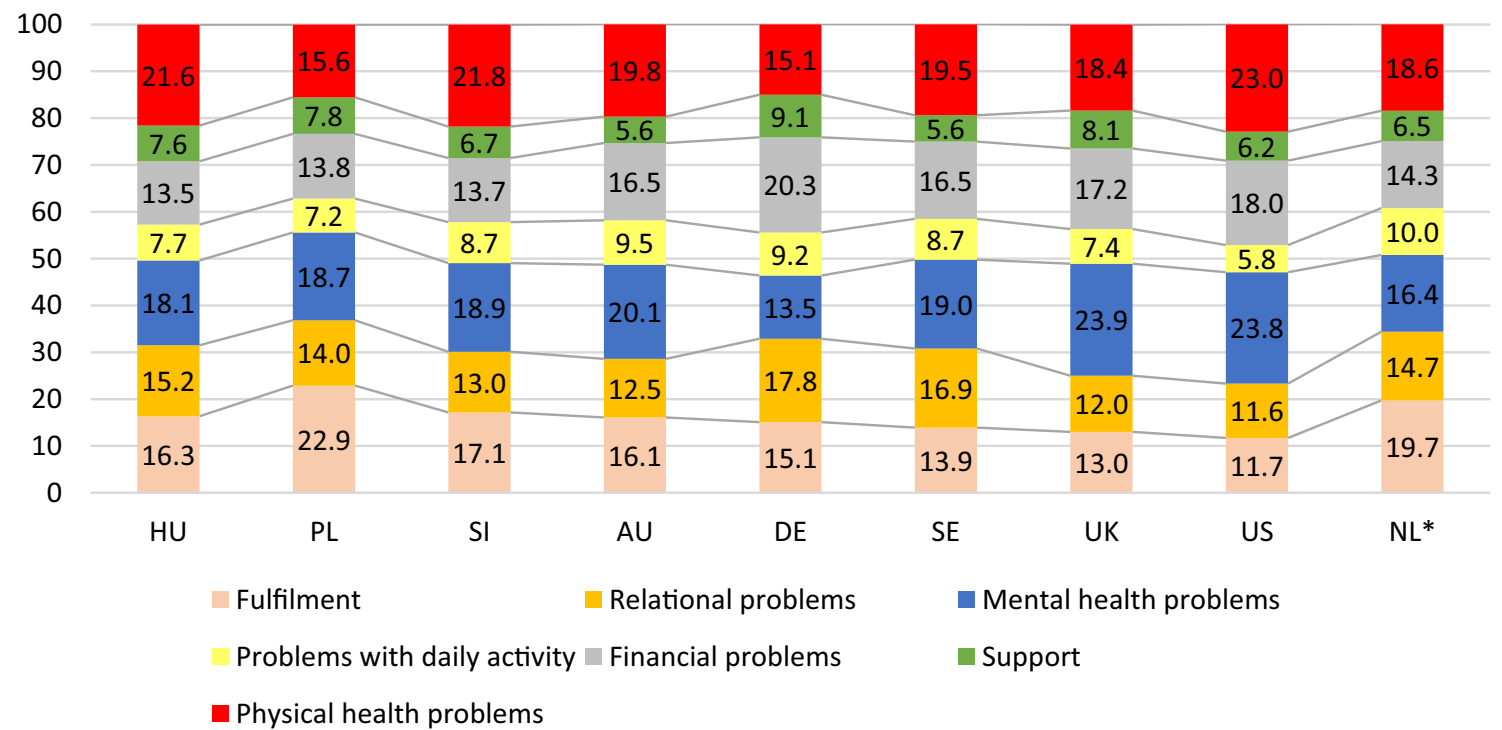

Fig. 1 Weights of attributes in the best scenario (CarerQol-7D 100), comparison with existing value sets. *The Dutch value set includes the interaction term between 'No physical health problems' and 'No mental health problem' (with the value of 6.6). This was added to 'No physical health problems' and 'No mental health problem' domains for this illustration in proportion of the tariffs of 'No physical health problems' and 'No mental health problem' (i.e. 3.5 and 3.1). $A U$ Australia, $D E$ Germany, $H U$ Hungary, $N L$ The Netherlands, $P L$ Poland, SE Sweden, SI Slovenia, UK United Kingdom, US United States 


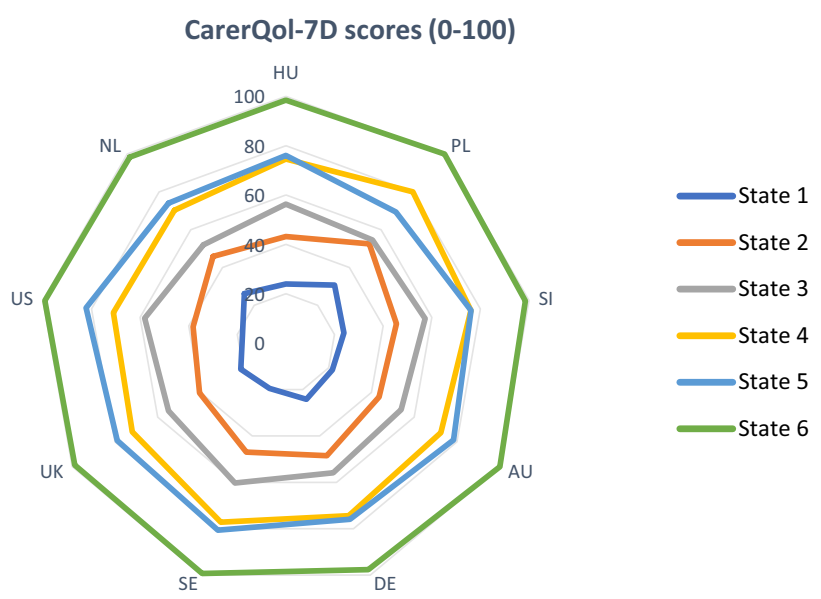

\begin{tabular}{|l|c|l|l|l|l|l|l|l|}
\hline States & Fulfilment & $\begin{array}{l}\text { Relational } \\
\text { problems }\end{array}$ & $\begin{array}{l}\text { Mental } \\
\text { health } \\
\text { problems }\end{array}$ & $\begin{array}{l}\text { Problems } \\
\text { with daily } \\
\text { activity }\end{array}$ & $\begin{array}{l}\text { Financial } \\
\text { problems }\end{array}$ & Support & $\begin{array}{l}\text { Physical } \\
\text { health } \\
\text { problems }\end{array}$ & Description \\
\hline State 1 & 3 & 3 & 3 & 3 & 3 & 3 & 3 & $\begin{array}{l}\text { A lot of problems in all domains, but also a lot of } \\
\text { fulfilment and support }\end{array}$ \\
\hline State 2 & 2 & 2 & 3 & 2 & 2 & 2 & 3 & $\begin{array}{l}\text { A lot of problems with physical and mental health, } \\
\text { some problems in other domains, some fulfilment } \\
\text { and support }\end{array}$ \\
\hline State 3 & 1 & 2 & 2 & 2 & 2 & 1 & 2 & $\begin{array}{l}\text { Some problems in all domains, no fulfilment, no } \\
\text { support }\end{array}$ \\
\hline State 4 & 2 & 2 & 2 & 2 & 2 & 2 & 2 & $\begin{array}{l}\text { Some problems in all domains, and some fulfilment } \\
\text { and support }\end{array}$ \\
\hline State 5 & 1 & 1 & 1 & 1 & 1 & 1 & 1 & $\begin{array}{l}\text { No problems in all domains, but also no fulfilment or } \\
\text { support }\end{array}$ \\
\hline State 6 & 3 & 1 & 1 & 1 & 1 & 2 & 1 & $\begin{array}{l}\text { No problems in all domains, a lot of fulfilment and } \\
\text { some support }\end{array}$ \\
\hline
\end{tabular}

Fig. 2 Radar plot CarerQol-7D scores of six different caregiving situations per country. ${ }^{\mathrm{a}}$ The most common caregiving state in CEE, representing $9.6 \%$ of caregiving situations. ${ }^{\mathrm{b}} \mathrm{Among}$ the most common caregiving states $\left(6^{\text {th }}\right)$ in CEE, representing $2.0 \%$ of caregiving situations. ${ }^{c}$ The second most common caregiving state in CEE, represent-

When choosing between caregiver situations in the DCE task, most of the respondents imagined that they provided care for their parents (Hungary $45.7 \%$, Poland $37.7 \%$, Slovenia $35.6 \%$ ) or their partners (Hungary $18.7 \%$, Poland 22.1\%, Slovenia 30.2\%). In Hungary and Slovenia, most respondents imagined that they lived in a different household (54.9 and 51.9\%), whereas in Poland most respondents imagined that they lived in the same household as the care recipient (59.1\%). In Hungary, Poland and Slovenia, $58.1 \%, 59.5 \%$ and $61.5 \%$ of respondents, respectively, imagined that the care recipient had mostly physical problems, $28.5 \%, 32.7 \%$ and $24.6 \%$ thought of both mental and physical problems, and $13.4 \%, 7.8 \%$, and $13.9 \%$ imagined the care recipient to have mostly mental health problems. Overall, 84-90\% of respondents imagined that they provided help with household activities. Other tasks they imagined were personal care (53-62\%), mobility (42-73\%) administrative tasks (40-76\%) and social support (37-50\%). Respondents imagined that they provided help to the care recipients for an average hours per week of $32 \pm 39$ in Hungary, $36 \pm 38$ in Poland and ing $2.8 \%$ of caregiving situations. The most common states in CEE were 2222222 (9.6\%), $3111121(2.8 \%), 3112121(2.8 \%), 3111131$ (2.5\%), 3112131 (2.5\%), and 1111111 (2.0\%). AU Australia, DE Germany, $H U$ Hungary, $N L$ The Netherlands, $P L$ Poland, SE Sweden, SI Slovenia, UK United Kingdom, US United States

$25 \pm 28$ in Slovenia for as long as $4.6 \pm 8.2,8.5 \pm 8.5$ and $8.7 \pm 13.0$ years, respectively.

\subsection{CarerQol-7D Tariffs for Hungary, Poland and Slovenia}

MMNL model estimates for the three countries are presented in Table 2. For all countries, all seven CarerQol-7D attributes were significantly associated with the choices made in the DCE and therefore the utility of informal care situations. As expected, the caregiving situations with more fulfilment and support and less problems in the negative caregiving domains were preferred in all three countries. Table 3 presents the CarerQol-7D tariffs for the three countries separately. Total utility scores for CarerQol-7D states can be calculated by adding up the scores for the relevant levels in each of the seven CarerQol-7D domains.

Figure 1 illustrates the relative weights of the seven domains, in case of the best level in all domains. In Hungary and Slovenia, 'physical health problems' and 'mental health problems' contributed most to the overall utility 
Table 1 Sociodemographic characteristics of respondents

\begin{tabular}{|c|c|c|c|}
\hline Variables & Hungary & Poland & Slovenia \\
\hline$N$ & 1000 & 1000 & 1000 \\
\hline Female & 51.2 & 52.5 & 52.4 \\
\hline \multicolumn{4}{|l|}{ Education } \\
\hline Primary & 23.1 & 11.1 & 17.6 \\
\hline Secondary & 37.4 & 66.7 & 55.8 \\
\hline Tertiary & 39.5 & 22.2 & 26.6 \\
\hline \multicolumn{4}{|l|}{ Employment status } \\
\hline Employed full time/self-employed & 44.2 & 45.5 & 48.7 \\
\hline Working part time & 5.6 & 8.2 & 3.5 \\
\hline Pensioner & 35.0 & 18.5 & 18.6 \\
\hline Disability pensioner & 3.7 & 6.6 & 7.1 \\
\hline Student & 1.3 & 3.4 & 7.9 \\
\hline Unemployed (seeking a job) & 4.2 & 6.8 & 8.4 \\
\hline Unemployed (not seeking a job) & 0.6 & 2.1 & 2.9 \\
\hline Homemaker/housewife & 3.0 & 6.8 & 1.5 \\
\hline Other & 2.4 & 2.1 & 1.4 \\
\hline \multicolumn{4}{|l|}{ Settlement type } \\
\hline Capital & 21.9 & 10.7 & 23.2 \\
\hline Town & 53.5 & 69.0 & 46.7 \\
\hline Village & 24.6 & 20.3 & 30.1 \\
\hline Partner (yes) & 62.2 & 68.5 & 59.6 \\
\hline \multicolumn{4}{|l|}{ Self-reported health } \\
\hline Excellent & 5.2 & 5.8 & 22.2 \\
\hline Very good & 21.8 & 27.1 & 32.0 \\
\hline Good & 40.6 & 43.7 & 29.4 \\
\hline Fair & 28.0 & 19.7 & 12.4 \\
\hline Poor & 4.4 & 3.7 & 4.0 \\
\hline \multicolumn{4}{|l|}{ Caregiving experience } \\
\hline No experience & 41.3 & 39.6 & 54.8 \\
\hline Informal care recipient & 2.1 & 6.5 & 12.8 \\
\hline Formal informal care recipient & 1.4 & 3.8 & 3.0 \\
\hline Informal caregiver currently & 14.9 & 15.0 & 9.6 \\
\hline Former informal caregiver in the last 12 months & 7.9 & 5.2 & 4.2 \\
\hline Former informal caregiver in the past & 14.7 & 10.8 & 5.7 \\
\hline Knowing someone who receives or provide informal care & 17.7 & 19.1 & 9.9 \\
\hline
\end{tabular}

All data are presented as percentages unless otherwise noted score (highest weights), followed by 'fulfilment'. In Poland, 'fulfilment' was the most important domain for respondents followed by 'mental health problems' and 'physical health problems'. In all three countries, 'relational problems' and 'financial problems' were in fourth or fifth place, whereas the least important domains were 'problems with daily activity' and 'support'.

\subsection{Comparison to Existing Value Sets}

Figure 1 also provides the relative weights for the reference countries. It suggests a common pattern for Anglo-Saxon countries (the UK, the USA and Australia) and Sweden but a unique profile for Germany, where 'physical health problems' and 'mental health problems' ranked in fourth and fifth place. Tariffs for the Netherlands resembled tariffs obtained in Poland, where 'fulfilment' was the most important domain. In general, tariffs for the CEE countries followed a similar pattern as the existing value sets with two slight differences: in CEE countries, 'fulfilment' was valued more, whereas 'financial problems' were valued less.

The radar plot in Fig. 2 presents the CarerQol-7D scores of six selected caregiving situations for Hungary, Poland, Slovenia and the six reference countries. In general, the CarerQol-7D scores in the three CEE countries resembled those in the reference countries. The ranking of the CarerQol-7D 
Table 2 Mixed multinomial logit results
Table 3 CarerQol-7D tariffs

\begin{tabular}{|c|c|c|c|c|c|c|c|c|c|}
\hline & \multicolumn{3}{|c|}{ Hungary } & \multicolumn{3}{|l|}{ Poland } & \multicolumn{3}{|c|}{ Slovenia } \\
\hline & Coeff. & SE & $p$ value & Coeff. & SE & $p$ value & Coeff. & SE & $p$ value \\
\hline \multicolumn{10}{|c|}{ Fulfilment (ref. no) } \\
\hline Some & 0.8258 & 0.1124 & 0.0000 & 0.6981 & 0.1154 & 0.0000 & 0.8586 & 0.0960 & 0.0000 \\
\hline A lot & 1.1036 & 0.1465 & 0.0000 & 0.9017 & 0.1492 & 0.0000 & 1.0807 & 0.1276 & 0.0000 \\
\hline \multicolumn{10}{|c|}{ Relational problems (ref. a lot) } \\
\hline No & 1.0201 & 0.1305 & 0.0000 & 0.5575 & 0.0802 & 0.0000 & 0.8180 & 0.0966 & 0.0000 \\
\hline Some & 0.7062 & 0.1147 & 0.0000 & 0.4515 & 0.0931 & 0.0000 & 0.5821 & 0.1105 & 0.0000 \\
\hline \multicolumn{10}{|c|}{ Mental health problems (ref. a lot) } \\
\hline No & 1.2211 & 0.1146 & 0.0000 & 0.7486 & 0.1034 & 0.0000 & 1.1937 & 0.1160 & 0.0000 \\
\hline Some & 0.9069 & 0.1004 & 0.0000 & 0.5430 & 0.0784 & 0.0000 & 0.8908 & 0.1049 & 0.0000 \\
\hline \multicolumn{10}{|c|}{ Problems with daily activities (ref. a lot) } \\
\hline No & 0.5157 & 0.0856 & 0.0000 & 0.2888 & 0.1042 & 0.0060 & 0.5504 & 0.1134 & 0.0000 \\
\hline Some & 0.3117 & 0.0740 & 0.0000 & 0.1773 & 0.0696 & 0.0110 & 0.4174 & 0.0873 & 0.0000 \\
\hline \multicolumn{10}{|c|}{ Financial problems (ref. a lot) } \\
\hline No & 0.9120 & 0.1010 & 0.0000 & 0.5459 & 0.1157 & 0.0000 & 0.8641 & 0.1067 & 0.0000 \\
\hline Some & 0.6689 & 0.0798 & 0.0000 & 0.4362 & 0.0825 & 0.0000 & 0.6810 & 0.0914 & 0.0000 \\
\hline \multicolumn{10}{|c|}{ Support (ref. no) } \\
\hline Some & 0.4132 & 0.0699 & 0.0000 & $0.3079^{\mathrm{a}}$ & 0.0575 & 0.0000 & 0.3291 & 0.0631 & 0.0000 \\
\hline A lot & 0.5142 & 0.0771 & 0.0000 & & & & 0.4226 & 0.0875 & 0.0000 \\
\hline \multicolumn{10}{|c|}{ Physical health problems (ref. a lot) } \\
\hline No & 1.4572 & 0.1533 & 0.0000 & 0.6325 & 0.1181 & 0.0000 & 1.3746 & 0.1170 & 0.0000 \\
\hline Some & 1.2060 & 0.1123 & 0.0000 & 0.5534 & 0.0828 & 0.0000 & 1.0403 & 0.0988 & 0.0000 \\
\hline
\end{tabular}

Coef. coefficient, ref. reference level, SE standard error

${ }^{a}$ Merged coefficient for some/a lot

\begin{tabular}{|c|c|c|c|c|c|c|c|}
\hline \multirow[t]{2}{*}{ CarerQol-7D domains } & \multirow[t]{2}{*}{ Level } & \multicolumn{2}{|c|}{ Hungary } & \multicolumn{2}{|c|}{ Poland } & \multicolumn{2}{|c|}{ Slovenia } \\
\hline & & Tariff & SE & Tariff & SE & Tariff & SE \\
\hline \multirow[t]{3}{*}{ Fulfilment } & No & 0.0 & 0.0 & 0.0 & 0.0 & 0.0 & 0.0 \\
\hline & Some & 12.2 & 1.7 & 17.7 & 2.9 & 13.6 & 1.5 \\
\hline & A lot & 16.3 & 2.2 & 22.9 & 3.8 & 17.1 & 2.0 \\
\hline \multirow[t]{3}{*}{ Relational problems } & No & 15.2 & 1.9 & 14.0 & 2.0 & 13.0 & 1.5 \\
\hline & Some & 10.5 & 1.7 & 11.3 & 2.3 & 9.2 & 1.8 \\
\hline & A lot & 0.0 & 0.0 & 0.0 & 0.0 & 0.0 & 0.0 \\
\hline \multirow[t]{3}{*}{ Mental health problems } & No & 18.1 & 1.7 & 18.7 & 2.6 & 18.9 & 1.8 \\
\hline & Some & 13.5 & 1.5 & 13.6 & 2.0 & 14.1 & 1.7 \\
\hline & A lot & 0.0 & 0.0 & 0.0 & 0.0 & 0.0 & 0.0 \\
\hline \multirow[t]{3}{*}{ Problems with daily activities } & No & 7.7 & 1.3 & 7.2 & 2.6 & 8.7 & 1.8 \\
\hline & Some & 4.6 & 1.1 & 4.6 & 1.8 & 6.6 & 1.4 \\
\hline & A lot & 0.0 & 0.0 & 0.0 & 0.0 & 0.0 & 0.0 \\
\hline \multirow[t]{3}{*}{ Financial problems } & No & 13.5 & 1.5 & 13.8 & 2.9 & 13.7 & 1.7 \\
\hline & Some & 9.8 & 1.2 & 11.1 & 2.1 & 10.8 & 1.5 \\
\hline & A lot & 0.0 & 0.0 & 0.0 & 0.0 & 0.0 & 0.0 \\
\hline \multirow[t]{3}{*}{ Support } & No & 0.0 & 0.0 & 0.0 & 0.0 & 0.0 & 0.0 \\
\hline & Some & 6.1 & 1.0 & 7.8 & 1.4 & 5.2 & 1.0 \\
\hline & A lot & 7.6 & 1.1 & 7.8 & 1.4 & 6.7 & 1.4 \\
\hline \multirow[t]{3}{*}{ Physical health problems } & No & 21.6 & 2.3 & 15.6 & 3.0 & 21.8 & 1.9 \\
\hline & Some & 17.9 & 1.7 & 13.9 & 2.1 & 16.5 & 1.6 \\
\hline & A lot & 0.0 & 0.0 & 0.0 & 0.0 & 0.0 & 0.0 \\
\hline
\end{tabular}

$S E$ standard error 
scores of the six states was identical across countries, except for one case. In Poland, state 4 (some problems in all domains) was valued higher than state 5 (no problems in any domains, but also no fulfilment and support). This was not surprising in light of the finding that fulfilment was the domain receiving the most weight in Poland.

Using local tariffs for the calculation of care-related quality of life of informal caregivers gave a different result than using one of the existing tariff sets for all three samples. For instance, if using the Dutch tariffs for all three countries, CarerQol-7D scores of current informal caregivers were 76.0 in Hungary, 69.6 in Poland and 70.9 in Slovenia. When using the local tariffs, these scores were 78.5, 75.7 and 75.0, respectively. Hence, we can notice that, when using local tariffs, scores became closer to each other and even the order of the scores changed.

\section{Discussion}

In this study, we obtained population-based tariff sets for the CarerQol-7D in Hungary, Poland and Slovenia. In all three countries, all seven domains and levels of functioning captured in the CarerQol-7D instrument were significantly associated with the observed choices and therefore carerelated utility. Domains contributing most to utility scores were 'physical health problems', 'mental health problems' and 'fulfilment', whereas 'problems with daily activity' and 'support' contributed least.

Value sets were comparable across the countries, although 'fulfilment' received more weight in Poland than in the other two countries. While such country differences may also relate to sampling issues or different language versions of the questionnaires, they may also reflect genuine differences in preferences for care states across countries. Indeed, Germany and the Netherlands were also shown to differ to some extent from Anglo-Saxon countries and Sweden [13]. In previous studies, religiosity and family values were found to play a role in the willingness to provide care $[20,21]$. The Polish population is considered to be more religious than those of the other two CEE countries [22], therefore we assume this may partly explain the slightly different attitudes found in the Polish sample towards informal care and the role of the family. We also suppose that preferences and subjective expectations for living circumstances when in need of or providing care might influence the valuation of caregiving situations. According to the Health and Long-Term Care Eurobarometer survey 2007, in Poland, the majority of the population (59\%) thought that the best option for older people who can no longer manage to live alone without regular help because of health problems is to live with one of their children [23]. This percentage is clearly higher than in Hungary (36\%) and Slovenia (29\%)
[23]. Thus, observed differences may reflect real differences in attitudes, which is also reflected in observed caregiving patterns. In Poland, actual caregiving situations (based on the characteristics of informal caregivers in our sample) differed somewhat from those in the other two countries. In particular, the average age of caregivers was lower (45.6 years in Poland, 56.1 years in Hungary and 48.0 years in Slovenia) [16]. Also, most of the Polish informal caregivers lived in the same household as the care recipient (56.0\%), whereas these shares were lower in Hungary (34.2\%) and Slovenia (39.6\%) [16].

One might expect the valuation of different domains to reflect the prevalence of problems in caregivers. The relatively low subsample size of informal caregivers $(N=395$ [13.2\%]) meant we could not analyse this relationship in depth. Although the problems reported by this subsample cannot be matched directly with the tariffs derived from the total sample, it is worth noting some contrasts. Informal caregivers reported the most problems in the 'support' and 'problems with daily activities' domains (10 and 9\%, respectively) [16], whereas these domains contributed the least to the CarerQol utility score. Similarly, informal caregivers reported the least problems in the "mental health problems' domain (6\%), whereas the impact of this domain on the utility score was the second highest across the seven domains. The 'anxiety/depression' dimension of the EQ5D-5L allows some indirect comparisons with CarerQol-7D 'mental health problems' on the total sample level. In the three countries, a total of $41 \%$ of the respondents reported problems on the 'anxiety/depression' dimension, which may have contributed to the relatively high value attached to the 'mental health problems' CarerQol-7D dimension. However, this parallelism is rather questionable as problems in the 'anxiety/depression' dimension are much more prevalent in the three CEE countries than in the six reference countries (with the EQ-5D-3L version: Slovenia 36\%, Hungary 35\%, Poland 33\%, Sweden 26\%, the USA 23\%, the UK 21\%, Germany $4 \%$, the Netherlands 4\%) $[24,25]$ and the CarerQol-7D 'mental health problems' utility weights did not follow this trend (Fig. 1). We suggest that future studies explore the impact of own health and informal care burden on the valuation of the CarerQol-7D.

Comparing the tariffs obtained in this study with existing value sets, we observed some noteworthy differences. For instance, in the CEE countries included in this study, 'fulfilment' was valued relatively highly, whereas 'financial problems' received a relatively low weight. These differences may partly reflect differences between CEE countries and the six reference countries in terms of economic situation and labour participation as well as attitudes towards informal care [26]. According to the previously mentioned Eurobarometer survey, a substantially lower share of the population in Western European countries considered the 
best option for an older person who no longer manages to live alone was to live with one of their children. In Sweden and the Netherlands, these shares were only $4 \%$, whereas in the UK it was $20 \%$ and in Germany it was 25\% [23].

Investigating country-specific tariffs allows cross-national comparisons and a better understanding of inter- and withincountry cultural differences in preferences. Local tariffs can be helpful in planning local health and social care strategies as these reflect which aspects of informal care are considered more important by the population and thus deserve more attention from health professionals and policy makers. In addition, the similarities and differences revealed in informal care preferences, both between CEE countries and the reference countries, but also across the CEE countries, add valuable new knowledge about the transferability of informal care burden studies and CarerQol-7D tariffs between jurisdictions. It is important to highlight that even minor differences in utility scores can eventually have clear implications for the results of an economic evaluation (also in incremental terms) and may thus influence reimbursement decisions. Minimally important differences have not been established for the CarerQol. Therefore, investigating the extent to which and under what circumstances the choice of tariff may induce meaningful differences are important areas for future research.

\subsection{Strengths and Limitations}

Some strengths and limitations of this study should be mentioned. First, the complexity of a DCE task such as the one used here in general can cause biased parameter estimates and large standard errors. In our study, a relatively high share of respondents, i.e. 22\% in Hungary, 35\% in Slovenia and $17 \%$ in Poland, fully agreed with the statement that it was difficult to answer the DCE questions. In the original Dutch study, this share was $16 \%$ [14]. Reasons provided by respondents for considering the DCE as difficult were having to choose between the two alternatives (65-80\%), assessing the attractiveness of an informal care situation (13-25\%), imagining being an informal caregiver (12-13\%) and reading the descriptions of the alternatives (6-9\%). These patterns were similar in the original Dutch survey [14]. Notwithstanding the importance of this finding that a substantial proportion of respondents considered the DCE difficult, the results of the study indicated logical answering patterns in the three samples, with less attractive states consistently receiving lower values and clear differentiation between the different domains.

Most respondents were familiar with informal caregiving (either as a provider or recipient) or knew someone who provided or received informal care. This may have made it easier for these respondents to imagine being a caregiver and to assess the caregiving situations. Current informal caregivers indeed reported fewer difficulties with completing the DCE task (19\% of caregivers strongly agreed it was difficult to complete the DCE task vs. $26 \%$ of non-caregivers). The caregiving situations respondents had in mind while performing the DCE resembled current informal care situations in the three countries relatively well in terms of the relation to the care recipient, experienced health problems, and living conditions. Respondents did imagine a slightly more extensive caregiving burden in terms of hours per week and duration of caregiving than actual figures in the three countries [16]. New studies might inform caregivers about these elements more, although this could come with the risk of giving less credible scenarios to individual respondents.

Second, we revealed noteworthy differences in national tariffs. Although we cannot rule out that some differences were related to sampling issues or other unexplored differences, these may reflect important differences in preferences for informal care states, even across CEE countries. Research explaining such differences further is relevant and encouraged.

Third, in this study, while we aimed for representativeness of our samples in terms of sex, age, education, and regional distribution, our use of an internet panel means the study samples might be somewhat selective. While this may limit the generalizability or full representativeness, our study design was similar to that of the previous studies, increasing the comparability of results across studies.

Finally, in the model, heterogeneity between subgroups of respondents was not considered, as the objective was to estimate tariffs at the population level. Again, this approach is in line with the previous studies that obtained CarerQol tariffs and aligns with the development of value sets for health measures, as these mostly reflect preferences of the whole population rather than the target population itself [27].

\section{Conclusions}

With this study, we have provided local value sets for the CarerQol instrument for Hungary, Poland and Slovenia, facilitating the evaluation of the effects of informal caregiving on the care-related quality of life of caregivers in these countries and the inclusion of the results in economic evaluations. CarerQol outcomes can be used as a primary outcome in economic evaluations of interventions mainly aimed at informal caregivers or can be presented as a separate component of economic evaluations of interventions aimed at patients (e.g. as one of the elements of a multicriteria decision analysis) to explicitly inform policy makers about the effects of interventions on caregivers. In any case, the quality of life of the large, important and often burdened group of informal caregivers deserves explicit attention in economic evaluation studies and health policy decisions. 
Acknowledgement Open access funding provided by Corvinus University of Budapest (BCE).

Author Contributions All authors contributed to the study conception and design. Material preparation, data collection and analysis were performed by PB, MF, DG, VP-R, RH, WBFB, JE, ZZ, LG, and MP. The first draft of the manuscript was written by $\mathrm{PB}, \mathrm{MF}$ and MP, and all authors commented on previous versions of the manuscript. All authors read and approved the final manuscript.

Data Availability The datasets generated and analysed during the current study are available from the corresponding author upon reasonable request.

\section{Compliance with Ethical Standards}

Funding This research was supported by the Higher Education Institutional Excellence Program of the Ministry of Human Capacities in the framework of the 'Financial and Public Services' research project (20764-3/2018/FEKUTSTRAT) at Corvinus University of Budapest.

Conflict of interest In connection with writing this article, PB, MF, and MP received grant support from the Higher Education Institutional Excellence Program of the Ministry of Innovation and Technology in the framework of the 'Financial and Public Services' research project (NKFIH-1163-10/2019) at Corvinus University of Budapest. DG, VR, $\mathrm{RH}, \mathrm{WB}, \mathrm{JvE}, \mathrm{ZZ}$ and LG have no conflicts of interest that are directly relevant to the content of this article.

Ethical approval All procedures performed in studies involving human participants were in accordance with the ethical standards of the institutional and/or national research committee (Hungarian Medical Research Council Nr. 35286-2/2018/EKU); the Bioethical Committee of the Medical University of Warsaw in Poland, AKBE/204/2018; and the National Medical Ethics Committee Nr. 0120-458/2018/4 in Slovenia) and with the 1964 Helsinki declaration and its later amendments or comparable ethical standards.

Informed consent Informed consent was obtained from all participants included in the study.

Open Access This article is licensed under a Creative Commons Attribution-NonCommercial 4.0 International License, which permits any non-commercial use, sharing, adaptation, distribution and reproduction in any medium or format, as long as you give appropriate credit to the original author(s) and the source, provide a link to the Creative Commons licence, and indicate if changes were made. The images or other third party material in this article are included in the article's Creative Commons licence, unless indicated otherwise in a credit line to the material. If material is not included in the article's Creative Commons licence and your intended use is not permitted by statutory regulation or exceeds the permitted use, you will need to obtain permission directly from the copyright holder.To view a copy of this licence, visit http://creativecommons.org/licenses/by-nc/4.0/.

\section{References}

1. OECD. Health at a Glance 2013: OECD Indicators. Paris: OECD Publishing; 2013. https://doi.org/10.1787/health_glance-2013en:oecd2013. Accessed 03 Feb 2020.
2. OECD. Health at a Glance 2017: OECD indicators. Paris: OECD Publishing; 2017. https://doi.org/10.1787/health_glance-2017-en. Accessed 03 Feb 2020.

3. Pendergrass A, Mittelman M, Graessel E, Özbe D, Karg N. Predictors of the personal benefits and positive aspects of informal caregiving. Aging Ment Health. 2019;23(11):1533-8.

4. Brouwer WB, van Exel NJA, van den Berg B, van den Bos GA, Koopmanschap MA. Process utility from providing informal care: the benefit of caring. Health Policy. 2005;74(1):85-99.

5. Van Exel J, Bobinac A, Koopmanschap M, Brouwer W. The invisible hands made visible: recognizing the value of informal care in healthcare decision-making. Expert Rev Pharmacoecon Outcomes Res. 2008;8(6):557-61.

6. Bobinac A, van Exel NJ, Rutten FF, Brouwer WB. Health effects in significant others: separating family and care-giving effects. Med Decis Mak. 2011;31(2):292-8.

7. Brouwer WBF. The inclusion of spillover effects in economic evaluations: not an optional extra. Pharmacoeconomics. 2019;37(4):451-6.

8. Hoefman RJ, van Exel J, Brouwer W. How to include informal care in economic evaluations. Pharmacoeconomics. 2013;31(12):1105-19.

9. Dixon S, Walker M, Salek S. Incorporating carer effects into economic evaluation. Pharmacoeconomics. 2006;24(1):43-53.

10. Al-Janabi H, McCaffrey N, Ratcliffe J. Carer preferences in economic evaluation and healthcare decision making. Patient. 2013;6(4):235-9.

11. Brouwer WB, van Exel NJ, van Gorp B, Redekop WK. The CarerQol instrument: a new instrument to measure care-related quality of life of informal caregivers for use in economic evaluations. Qual Life Res. 2006;15(6):1005-21.

12. Hoefman RJ, van Exel NJ, Looren de Jong S, Redekop WK, Brouwer WB. A new test of the construct validity of the CarerQol instrument: measuring the impact of informal care giving. Qual Life Res. 2011;20(6):875-87.

13. Hoefman RJ, van Exel J, Brouwer WBF. Measuring care-related quality of life of caregivers for use in economic evaluations: CarerQol tariffs for Australia, Germany, Sweden, UK, and US. Pharmacoeconomics. 2017;35(4):469-78.

14. Hoefman RJ, van Exel J, Rose JM, van de Wetering EJ, Brouwer WB. A discrete choice experiment to obtain a tariff for valuing informal care situations measured with the CarerQol instrument. Med Decis Mak. 2014;34(1):84-96.

15. Riedel M, Kraus M. Informal care provision in Europe: regulation and profile of providers. ENEPRI Research Report No 96; CEPS; 2011.

16. Baji P, Golicki D, Prevolnik-Rupel V, Brouwer WBF, Zrubka Z, Gulacsi L, et al. The burden of informal caregiving in Hungary, Poland and Slovenia: results from national representative surveys. Eur J Health Econ. 2019;20(Suppl 1):5-16.

17. Hensher DA, Greene WH. The mixed logit model: the state of practice. Transportation. 2003;30(2):133-76.

18. Train KE. Discrete choice methods with simulation. Cambridge: Cambridge University Press; 2009.

19. Green C, Brazier J, Deverill M. Valuing health-related quality of life. A review of health state valuation techniques. Pharmacoeconomics. 2000;17(2):151-65.

20. Goldberg-Looney LD, Perrin PB, Morlett-Paredes A, Mickens MN. College-age adults' religiosity, family functioning and values, and willingness to provide care for a relative with a chronic health condition. Rehabil Psychol. 2017;62(2):100-9.

21. Yoon KH, Moon YS, Lee Y, Choi SH, Moon SY, Seo SW, et al. The moderating effect of religiosity on caregiving burden and depressive symptoms in caregivers of patients with dementia. Aging Ment Health. 2018;22(1):141-7.

22. Jakubczyk M, Golicki D, Niewada M. The impact of a belief in life after death on health-state preferences: True difference or artifact? Qual Life Res. 2016;25(12):2997-3008. 
23. Eurobarometer S. Health and long-term care in the European Union. In: Special Eurobarometer. 2007. http://ec.europa.eu/commfronto ffice/publicopinion/archives/ebs/ebs_283_en.pdf. Accessed 3 Feb 2020.

24. Janssen B, Szende A. Population Norms for the EQ-5D. In: Szende A, Janssen B, Cabases J, editors. Self-reported population health: an international perspective based on EQ-5D, Dordrecht. 2014. p. 19-30.

25. Golicki D, Niewada M. General population reference values for 3-level EQ-5D (EQ-5D-3L) questionnaire in Poland. Pol Arch Med Wewn. 2015;125(1-2):18-26.
26. Péntek M, Hajdu O, Rencz F, Beretzky Z, Brodszky V, Baji P, et al. Subjective expectations regarding ageing: a cross-sectional online population survey in Hungary. Eur J Health Econ. 2019;20(Suppl. 1):17-30.

27. Versteegh M, Brouwer W. Patient and general public preferences for health states: a call to reconsider current guidelines. Soc Sci Med. 2016;165:66-74. 